\title{
108 Accelerated 3D tagging to assess left ventricular dyssynchrony in patients with sub-acute myocardial infarctions Andrea K Rutz ${ }^{* 1}$, Sebastian Kozerke ${ }^{1}$, Peter Boesiger ${ }^{1}$ and Juerg Schwitter ${ }^{2}$
}

\author{
Address: ${ }^{1}$ Institute for Biomedical Engineering, University and ETH, Zurich, Switzerland and ${ }^{2}$ Clinic of Cardiology, University Hospital, Zurich, \\ Switzerland \\ * Corresponding author
}

from I I th Annual SCMR Scientific Sessions

Los Angeles, CA, USA. I-3 February 2008

Published: 22 October 2008

Journal of Cardiovascular Magnetic Resonance 2008, I0(Suppl I):A9 doi:10.1 I86/I532-429X-10-SI-A9

This abstract is available from: http://jcmr-online.com/content/I0/SI/A9

(c) 2008 Rutz et al; licensee BioMed Central Ltd.

\section{Introduction}

Cardiac resynchronization therapy (CRT) proved successful in larger patient populations. However, individual responsiveness to CRT is not yet highly predictable. Around 30\% of patients do not appear to benefit from CRT [1]. Accurate measurement of dyssynchrony could help in discriminating CRT responders from nonresponders. Individual responsiveness of patients could be improved with the knowledge of temporally resolved, regional motion patterns. The acquisition of multi-slice MR tagging data [2] covering the whole heart in short- and long axis orientations is associated with long acquisition times and prone to slice misregistration. A novel accelerated $3 \mathrm{D}$ tagging acquisition scheme $[3,4]$ allows assessing detailed 3D motion patterns of the entire left ventricle (LV) in only three breath-holds. Accordingly, the method is easily integrated into a clinical protocol including volumetric, perfusion and viability measurements.

The 3D tagging technique was applied to quantify LV dyssynchrony in patients with sub-acute myocardial infarctions as a model causing dyssynchrony relative to healthy controls. Features of three-dimensional motion patterns were correlated with the presence of scar tissue as measured with late enhancement images.

\section{Purpose}

To quantify the spatial extent and temporal characteristics of LV dyssynchrony in controls and patients with subacute myocardial infarctions by application of a novel 3D tagging technique in combination with CMR viability imaging.

\section{Methods}

3D CSPAMM-tagged [5] images of the entire LV were acquired in 16 patients ( 14 male/2 female, age $=60.7 \pm$ 11.5 years) with sub-acute myocardial infarctions and in 17 controls ( 9 male $/ 8$ female, age $=36.0 \pm 13.9$ years ) . Patients were measured 10.5 days (minimum 2 days, maximum 39 days) after myocardial infarction and showed an ejection fraction of $40.7 \pm 9.5 \%$. A hybrid multi-shot, segmented echo-planar imaging sequence was applied to acquire motion encoded data in all three orthogonal directions (Philips 1.5 T, Best, NL) $[3,4]$. Spatial resolution in each encoding direction was $3.0 \times 7.7 \times$ $7.7 \mathrm{~mm}^{3}$ with a temporal resolution of $30 \mathrm{~ms}$. Data acquisition was split into three breath-holds of 18 heartbeats duration each. For viability assessment late enhancement images were acquired in all patients (Gadovist, 0.25 $\mathrm{mmol} / \mathrm{kg})$.

Midwall circumferential shortening (csh, \%) and time to maximum csh $\left(\mathrm{T}_{\max }\right)$ were extracted from 48-66 segments/heart using a home-written peak-combination HARP $[6,7]$ software. The standard deviation of $\mathrm{T}_{\max }$ of all segments was calculated as a measure of LV dyssynchrony. In addition, for each segment the absolute time difference $\left(\mathrm{T}_{\text {diff }}\right)$ for maximum $c$ sh relative to the mean $\mathrm{T}_{\max }$ of the entire LV was calculated. 


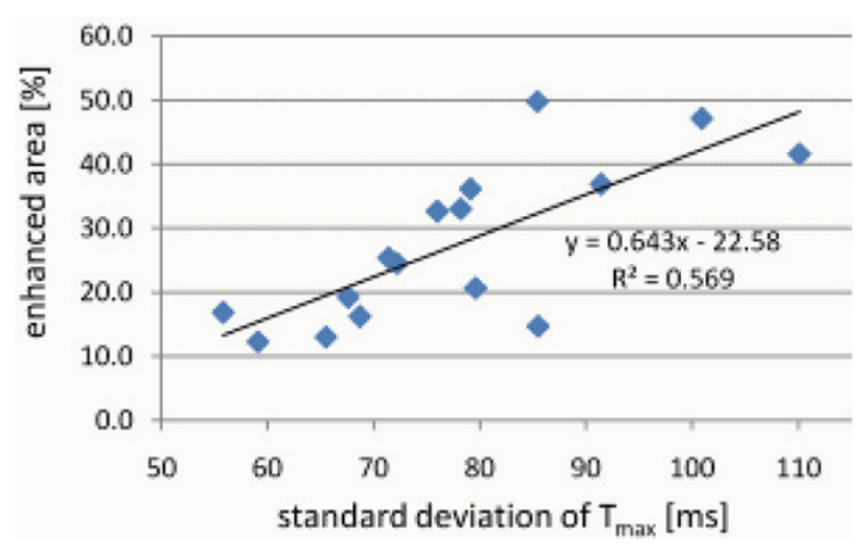

Figure I

Linear regression between LV dyssynchrony and amount of scar tissue for patients with sub-acute myocardial infarctions $(p<0.01)$.

\section{Results}

In patients, $\mathrm{T}_{\max }$ of $351.7 \pm 34.7 \mathrm{~ms}$ was not different from the controls with $351.4 \pm 39.2 \mathrm{~ms}$. However, the standard deviation of $\mathrm{T}_{\text {max }}$, which served as a measure of dyssynchrony, was significantly higher in patients $(77.9 \pm 14.4$ ms vs. $43.9 \pm 9.1 \mathrm{~ms}, \mathrm{p}<0.0001)$ and linearly dependent on LV enhanced area (Fig. 1, p < 0.01). Mean LV csh at end-systole was significantly reduced in patients $(12.0 \pm$ $3.3 \%)$ compared to healthy volunteers $(18.1 \pm 1.9 \%$, p < 0.0001). Similarly, the standard deviation of LV csh at end-systole was different between patients $(7.0 \pm 1.1 \%)$ and controls $(4.3 \pm 0.7 \%, \mathrm{p}<0.0001)$. Results for a representative patient with anterior myocardial infarction are shown in Fig. 2.

\section{Conclusion}

Accelerated 3D MR tagging acquisition provides detailed information on dyssynchrony of the entire left ventricle. In combination with viability information obtained from

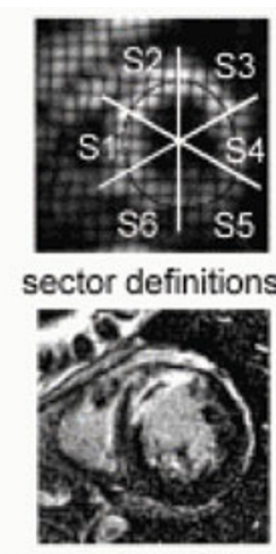

a equatorial
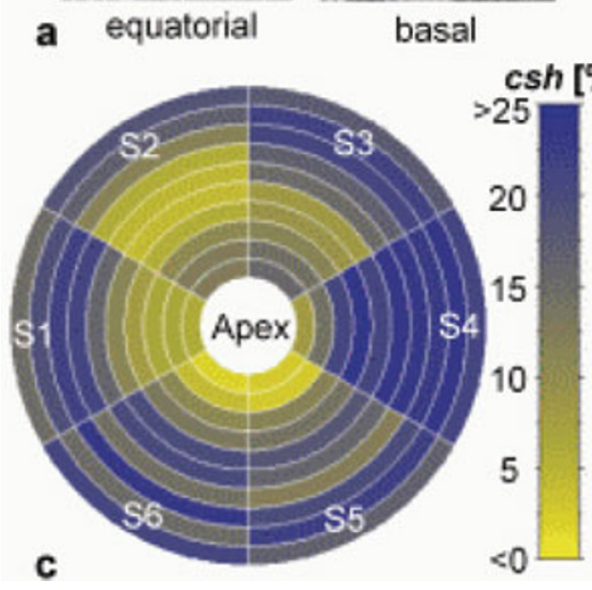

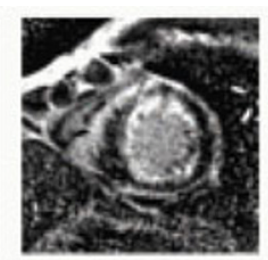

apical

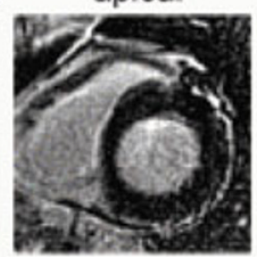

basal

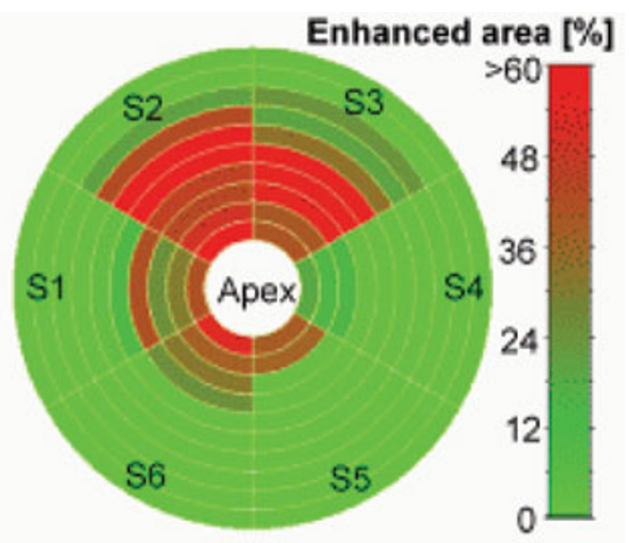

b

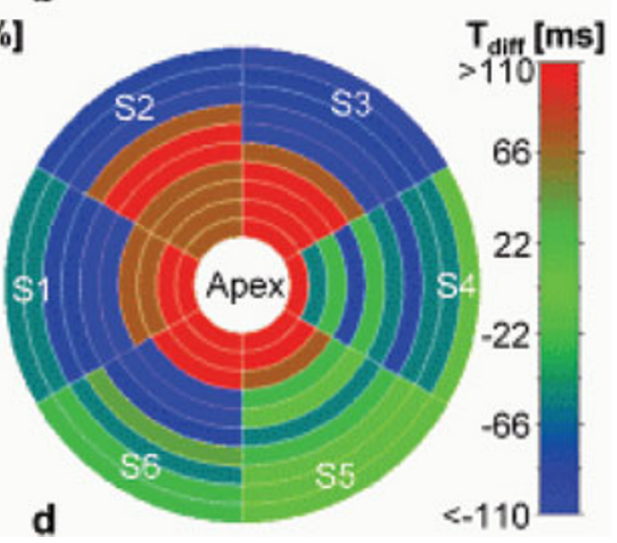

Figure 2

Results for a representative patient with anterior myocardial infarction. (a) Tagged image (slice through 3D data set) with sector definitions and exemplary late enhancement imges on 3 cardiac levels. (b) Polar map of viability: Regions exhibiting late enhancement due to scar tissue. (c) Polar map of deformation: Circumf. shortening (csh) at end-systole. (d) Polar map of dyssynchrony: Time difference $T_{\text {diff }}$ map for maximum csh relative to the mean $T_{\max }$. Blue $=$ early, red $=$ delayed, green $=$ regular timing of contraction. 
late enhancement images, this approach shows potential to quantify both dyssynchrony and scar fast and accurately and thus may prove an important measure for CRT planning.

\section{References}

I. Kass DA: J Cardiovasc Electrophysiol 2005, 16:35-4I5.

2. Axel L, et al.: Radiology 1989, 17 I (3):84|-845.

3. Rutz AK, et al:: Proc ISMRM 2007, 759:

4. Rutz AK, et al:: MRM in press.

5. Fischer SE, et al.: MRM 1993, 30:191-200.

6. Osman N, et al.: MRM 1999, 42(6): 1048-60.

7. Ryf S, et al.: JMRI 2004, 20:874-8.

Publish with Biomed Central and every scientist can read your work free of charge

"BioMed Central will be the most significant development for disseminating the results of biomedical research in our lifetime. " Sir Paul Nurse, Cancer Research UK

Your research papers will be:

- available free of charge to the entire biomedical community

- peer reviewed and published immediately upon acceptance

- cited in PubMed and archived on PubMed Central

- yours - you keep the copyright

Submit your manuscript here:

http://www.biomedcentral.com/info/publishing_adv.asp 